\title{
UTILIZATION OF OPERATION THEATRE;
}

\author{
A newly developed tertiary care teaching hospital
}

Dr. Nighat Bakhtiar, Dr. Masood Jawaid, Dr. Abdul Khalique, Prof. Pervez Iqbal

ABSTRACT... Objective: To find out the number and variety of different surgeries performed at the operation theatre of the Dow University Hospital. Methods: From January 2011 to December 2011, hospital operation theatre record was reviewed. Main outcome measures were age, gender, medical record (MR) number, name of operations with their indications, specialty and type of anesthesia used during the procedure, type of surgery. Monthly trend of surgeries were also evaluated. Results: The total numbers of operations performed during first year of operation theatre working were 539 cases. Number of emergency surgeries done was $42(7.79 \%)$ and elective were 497 (92.2\%).Surgeries performed by General Surgery, Gynecology and Plastic surgery department were 319 (59.18\%), 61 (11.3\%), 54 (10.0\%). MR Number was not present in record register in 306 (56.7\%) cases, indication for surgery was not written in 274 (50.8\%) cases and name of surgery was missing in $18(3.3 \%)$ cases. The most common case performed were different types of biopsies while other common cases performed in the year 2011 were incision and drainage, cholecystectomies and hernia repair. Conclusions: The record maintained was overall satisfactory however needs further improvement. Computerization of records with training of staff about its proper maintenance can improve its quality with international standards.

Key words: Utilization, operation theatre, audit, pattern

Article Citation

Bakhtiar N, Jawaid M, Khalique A, Iqbal P. Utilization of operation theatre; a newly developed tertiary care teaching hospital. Professional Med J 20(6): 1048-1052.

\section{INTRODUCTION}

A properly structured operation theatre is a vital and necessary part of anyhospital. The theory of operation theatre utilization is present in the surgical journalism as early as the late $1970 \mathrm{~s}^{1-3}$.

To satisfy patients, fulfill demands of surgeons and operation theater staff and to proof a well-functioning operation theater an excellent management is needed. Operation theatre needs a great quantity of resources to maintain a working function in any hospital ${ }^{4}$. It's always been a difficult and daring procedure, to improve the function and effectiveness of an operation theater in such a hospital where the health facilities and administration keep on changing frequently. To increase surgical output in any hospital its necessary an operation theater to be properly working under constantmnagment ${ }^{5}$.

In medical literature, it has been discussed that the hospital management and leadership plays an important role in the development of a proper functioning operation theater, but it also depends on many other factors as well. It depends on provision of multiple medical and surgical services like equipments, drugs, time utilization, sterilization and control of infections etc. Studies showed that the measurement of time utilization has always been of greater interest among researchers ${ }^{6,7}$. And it's obvious that an important component to increase the efficacy of any operation theater is time scheduling as it helps in planning the requirements, accessibility of equipments and ultimately develops a smooth running environment. Besides that many other factors like expediency, cost and infection control are also important in planning a newly developed operation theaters ${ }^{8,9}$. Many guidelines and rules are present in literatures and been followed but many hospitals in different countries ${ }^{10} .{ }^{T}$ monitor and evaluate the performance of any operation theater, an excellent quality data is require ${ }^{11}$ which is not properly and even not maintained in most of the hospitals, especially the newly developed one.

Dow University Hospital is a newly developed tertiary care teaching hospital attached with Dow International 
Medical College affiliated with Dow University of Health Sciences. To make this hospital to an international standard, administration is planning to build every part of this hospital in its best eminence. This study is one of the initial audit reports of hospital and it is done with the intention that we document the present position of its utilization by different specialties and surgeries performed and its trend with time so that its utilization can be improved further.

\section{METHODOLOGY}

A cross-sectional study was done during one year period from January 2011 to December 2011 form hospital operation theatre record which was manually maintained in a log register. The recorded variables in the study were age, gender, medical record (MR) number, name of operations with their indications for operation. In addition to this field specialty and type of anesthesia used during the procedure in the theatre were recorded. Beside this comparison between number of elective and emergency surgeries was performed.

The data was recorded on Excel spread sheet and descriptive statistics were used.

\section{RESULTS}

The total numbers of operations performed during first year of operation theatre working (form January 2011 to December 2011) were 539 cases. Out of which $281(52.1 \%)$ patients were female and 258(47.86\%) were male. Number of emergency surgeries done was 42(7.79\%) and elective were 497(92.2\%).

Surgeries performed by General Surgery, Gynecology and Plastic surgery department were 319(59.18\%), $61(11.3 \%), 54(10.0 \%)$ respectively and their percentage distribution is shown in figure 1.

Total number of surgeries performed under General anesthesia were 284 (52.69\%), under spinal anesthesia 66(12.24\%), under Monitored Anesthesia

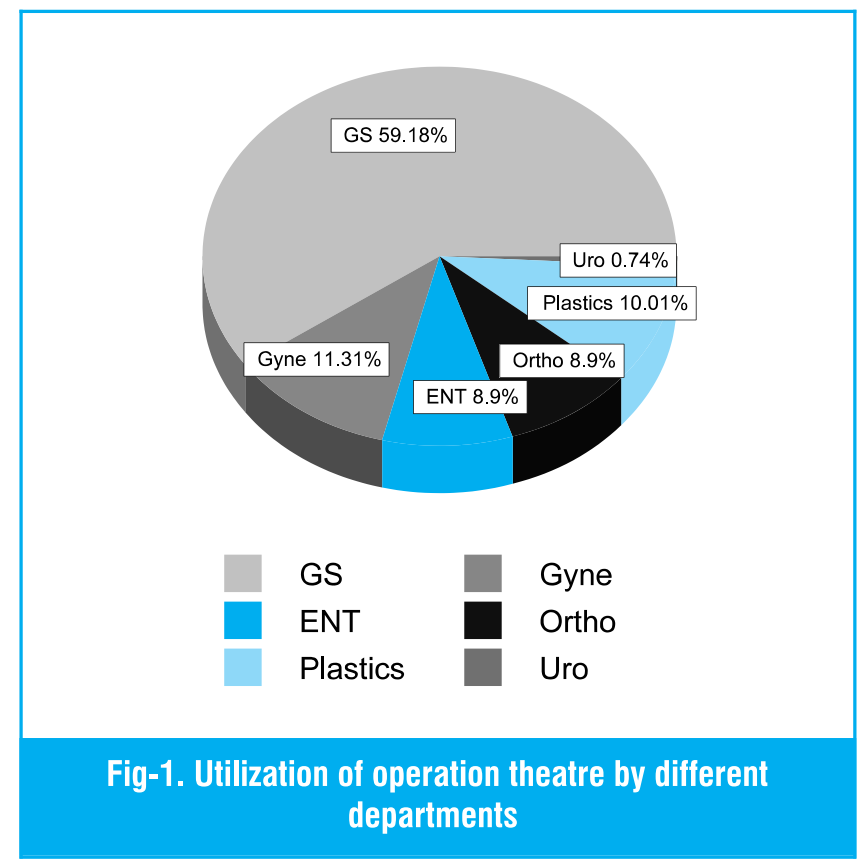

Care (MAC)14(2.59\%) and under local anesthesia were $175(32.46 \%)$.Maximum numbers of surgeries were done the month of October.(Table-I).

MR Number was not present in record register in 306 $(56.7 \%)$ cases, indication for surgery was not written in $274(50.8 \%)$ cases and name of surgery was missing in $18(3.3 \%)$ cases.

The most common case performed were different types of biopsies while other common cases performed in the year 2011 were Incision and drainage, Cholecystectomies and hernia repair (TableII).

\section{DISCUSSION}

Total 539 surgeries were performed in the year 2011 which is good number of cases in terms of first year of a hospital. However results showed that only 42 emergency procedures were performed. The most common surgery performed was excisional biopsy under local anesthesia, one reason being hospital situated with OJHA hospital of Chest Diseases and most of the patients were referred for lymph node biopsy. As anticipated, most of surgeries were 


\begin{tabular}{|c|c|c|c|c|c|}
\hline Months & $\begin{array}{c}\text { General } \\
\text { Anesthesia } 298 \\
(55.3 \%)\end{array}$ & $\begin{array}{c}\text { Local Anesthesia } \\
170(31.5 \%)\end{array}$ & $\begin{array}{c}\text { Spinal Anesthesia } \\
64(11.9 \%)\end{array}$ & $\begin{array}{c}\text { Monitored Care } \\
\text { Anesthesia } \\
7(1.3 \%)\end{array}$ & $\begin{array}{c}\text { Total Operation } \\
539(\mathbf{1 0 0 \% )}\end{array}$ \\
\hline January 2011 & - & 3 & - & - & 3 \\
\hline February 2011 & - & 6 & - & - & 6 \\
\hline March 2011 & 17 & 10 & 3 & - & 30 \\
\hline April 2011 & 31 & 15 & - & - & 46 \\
\hline May 2011 & 20 & 19 & - & 1 & 40 \\
\hline June 2011 & 36 & 23 & - & - & 59 \\
\hline July 2011 & 36 & 18 & 8 & 1 & 63 \\
\hline August 2011 & 15 & 12 & 9 & 1 & 37 \\
\hline September 2011 & 34 & 08 & 8 & 2 & 52 \\
\hline October 2011 & 30 & 29 & 18 & 2 & 79 \\
\hline November 2011 & 41 & 11 & 9 & - & 61 \\
\hline December 2011 & 38 & 16 & 9 & - & 63 \\
\hline
\end{tabular}

\begin{tabular}{|l|c|c|}
\hline Name of procedure & $\begin{array}{c}\text { No. of cases } \\
\mathbf{( 3 1 9 )}\end{array}$ & \%age of cases \\
\hline Biopsies & 114 & 35.7 \\
\hline Incision and drainage & 35 & 10.9 \\
\hline Cholecystectomies & 35 & 10.9 \\
\hline Hernioplasties & 28 & 8.77 \\
\hline Debridments & 23 & 7.2 \\
\hline Perineal surgeries & 22 & 6.89 \\
\hline Laparotomies & 18 & 5.64 \\
\hline Nail avulsions & 14 & 4.388 \\
\hline Endoscopies & 12 & 3.76 \\
\hline Circumcisions & 6 & 1.88 \\
\hline Appendectomies & 7 & 2.19 \\
\hline Miscellaneous & 5 & 1.56 \\
\hline
\end{tabular}

Table-ll. Details of general surgeries performed

performed by general surgical team.

The management of any operation theater is a very important and sensitive matter. A lot of studies have been carried out on effectiveness of Operation Theater. A major part of which discussed issues of management, timing schedule, functioning ${ }^{12,13}$ but only some of them discussed that how these deficiencies can be decreased ${ }^{14}$. After collection of data during this study it was perceived that a properly maintained entry data and documentation of cases is essential to evaluate the efficiency of any operation theater in a hospital. Apart from proper data entry of patients log, a good quality of operative notes is a must in any hospital15 and even they can be used for the teaching and learning purposes ${ }^{16}$.

There weresome major deficiencies in the record which needs serious attention. The chief deficiency of our study was incomplete data in log register. The timing of surgeries was not mentioned in many logs. 
Data was maintained in paper register which can easily be faded with time. Properly entered computerized data entry is needed to record whatever done in the operation theater. It's necessary to educate the staff and junior doctors regarding equipment usage, management of cases, time scheduling, recent advances and importance of record. The availability of staff and anesthetist at late hours can increase the quantity and quality of procedures done in the operation theater.

Such audits should be done on yearly basis to maintain proper records and to check effective utilization of Operation theatre. Every department and sub specialty units should be encouraged to take active part in it so it will ultimately make our goal of making a well developed hospital fulfilled.

\section{CONCLUSIONS}

The overall utilization of Operation Theater of Dow University Hospital was goodduring the first year of its working. The record maintained was overall satisfactory however needs further improvement. Computerization of records with training of staff about its proper maintenance can improve its quality with international standards.

Copyright(c) 15 Jul, 2013.

\section{REFERENCES}

1. Magerlein JM, Martin JB.Surgical demand scheduling: a review. Health ServRes.1978;13 (4):418-33.

2. Quayle SN. Efficient costing and budgeting in the operating theatre. Natnews. 1978;15(2):11-4.

3. Faiz O, Tekkis P, Mcguire A, Papagrigoriadis S, Rennie J, Leather $A$. Is theatre utilization a valid performance indicator for NHS operating theatres? BMC health services research. 2008;8(1):28.

4. Shah J, Ansari A,Bhattacharyya .Cancellation of Urologyoperations. Clinical Governance J.2006; 11(2): 128- 133.
5. Reena Kumar. Kumar R, Sarma R. Operation Room Utilization at AIIMS, a Prospective Study. Journal of the Academy of Hospital Administration.2003;15(1):16.

6. Dexter F, Abouleish AE, Epstein RH, Whitten CW, Lubarsky DA. Use of operating room information system data to predict the impact of reducing turnover times on staffing costs. Anesthesia \& Analgesia. 2003;97(4):1119-26.

7. Donald C, Caroline A, Chen $\mathrm{CH}$. Optimum. Operating Room Utilization. Anesth Analg.2003; 96:1114-21.

8. Humphreys $\mathrm{H}$. Infection control and design of a new operating theatre suite. Journal of Hospital Infections. 1993; 23(1):61-67.

9. Essex-Lopresti M. Operating theatre design. The Lancet. 1999;353(9157):1007-10.

10. Kikuchi $\mathrm{H}$. Infection control in operation theaters: preface and comments. Masui. 2010;59(5):554-5.

11. Littlejohns P, Watt JC and Rawlinson J. An Evaluation programme for Hospital Information System Northern Province.1999. Available from URL: http://www.bmj.com/highwire/filestream/440656/field _highwire_adjunct_files/0

12. Vinukondaiah K, Ananthakrishnan N, Ravishankar M. Audit of operation theatre utilization in general surgery. National Medical Journal of India. 2000;13(3):118-20.

13. Zafar A, Saeed T,Griffin S,Ahmed S, Ansari JA. Cancelled elective general surgical operations in Ayub Teaching Hospital. J Ayub Med Coll.2007; 19(3):64-66.

14. Wilkinson DS, Pifeleti F. General surgery in Tonga: an audit. Pacific Health Dialog.1999;6(2):199-201.

15. Jawaid M, Askari Raza, Qureshi MA, Manzar S. Quality of operative notes. J Postgrduate Med Inst. 2008; 22(4): 274-6.

16. Jawaid M, Masood Z, Humayun S. Operative Notes: A simple yet effective teaching resource for training. PakArmed Forces Med J. 2011;1. 


\section{AUTHOR(S):}

1. DR. NIGHAT BAKHTIAR, MBBS

Resident Surgery,

Dow University Hospital, Karachi - Pakistan.

2. DR. MASOOD JAWAID, MCPS, MRCS, FCPS

Assistant Professor Surgery,

Dow University Hospital and

Dow International Medical College,

Dow University of Health Sciences, Karachi - Pakistan

3. DR. ABDUL KHALIQUE, FCPS

Assistant Professor Surgery,

Dow University Hospital and

Dow International Medical College,

Dow University of Health Sciences Karachi - Pakistan

\section{Prof. Pervez Iqbal, FRCS}

Professor of Surgery

Dow University Hospital and

Dow International Medical College,

Dow University of Health Sciences, Karachi - Pakistan

Correspondence Address:

Dr. Masood Jawaid

Department of Surgery,

Dow International Medical College, masood@masoodjawaid.com

Article received on: 16/05/2013 Accepted for Publication: 15/07/2013 Received after proof reading: 03/12/2013

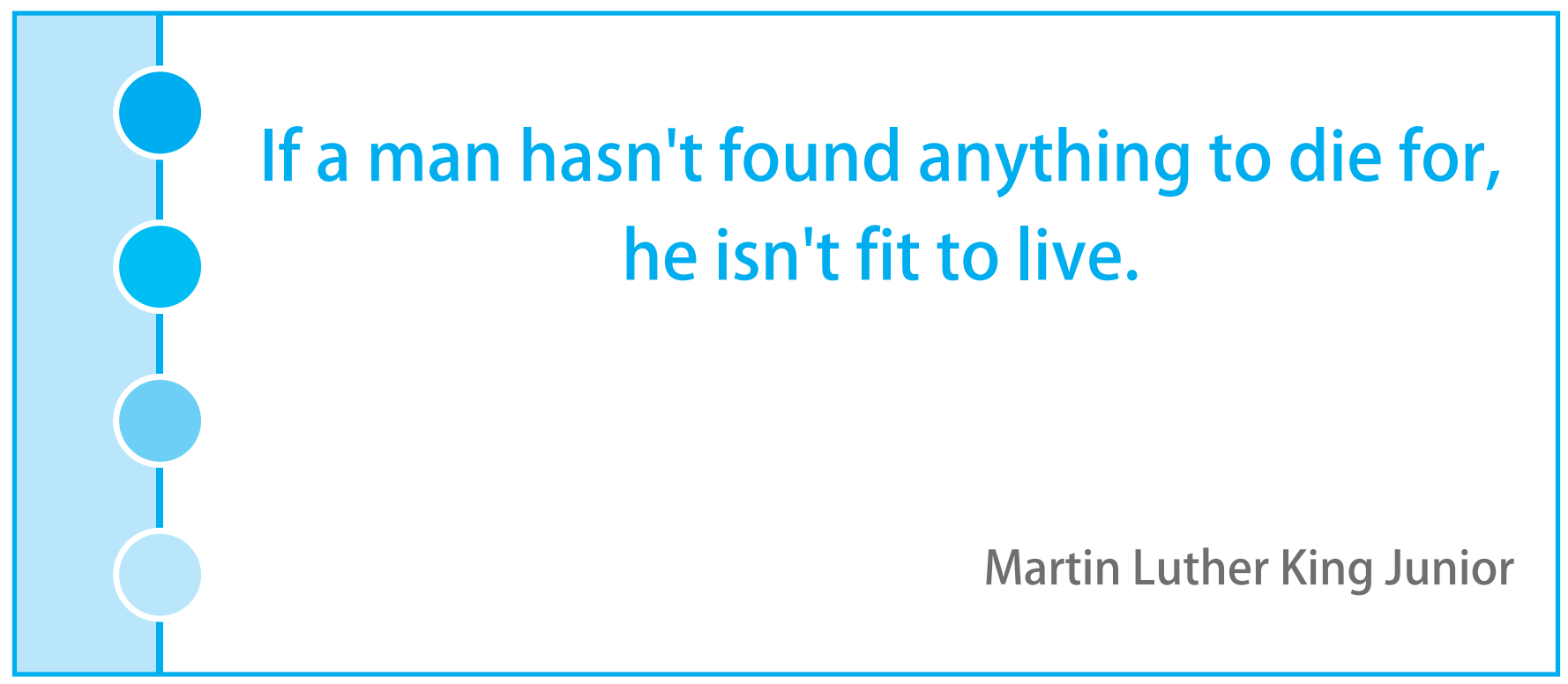

